\title{
Adenoma metanéfrico del riñón asociado a policitemia y eritromelalgia: caso clínico
}

\author{
NORMAN ZAMBRANO ${ }^{1,2}$, BRUNO VIVALDI $^{2,4}$, RICARDO ESPINOZA $^{3}$
}

\section{Metanephric adenoma of the kidney associated with polycythemia and erythromelalgia. Report of one case}

We report a 21-year-old male, presenting with erythromelalgia and polycythemia. A solid renal mass of the lower pole of the right kidney was discovered. The patient was subjected to a right open partial nephrectomy. The pathological study of the surgical specimen showed a metanephric adenoma of the kidney. The patient had an uneventful postoperative evolution. Currently the patient is in good health without evidence of recurrence of the tumor and normal hematological parameters.

(Rev Med Chile 2012; 140: 629-632).

Key words: Erythromelalgia; Kidney neoplasms; Polycythemia.

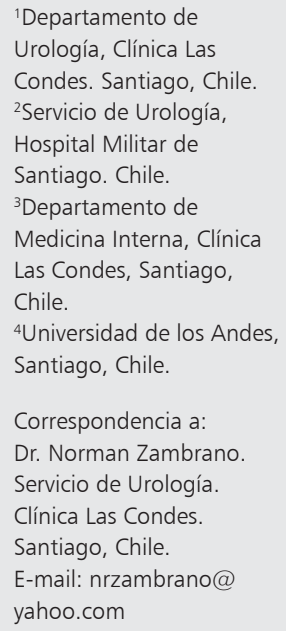

$\mathrm{E}$ 1 adenoma metanéfrico (AM) es un tumor renal raro, con alrededor de 100 casos descritos en la literatura ${ }^{1,2}$. Está catalogado como un tumor de curso benigno ${ }^{1}$, sin embargo, existen 2 reportes de casos metastásicos ${ }^{2,3}$. Estudios sugieren características histológicas similares a las del tumor de Wilms y al carcinoma renal papilar ${ }^{1,4}$. La rareza de este tumor, su potencial degeneración maligna y la dificultad para diferenciarlo de un carcinoma de células renales, obligan a su extirpación quirúrgica en la mayoría de los casos.

\section{Caso clínico}

Paciente masculino, de 21 años de edad, sin antecedentes mórbidos de importancia, quien consultó por eritromelalgia de dos años de evolución. En los exámenes de laboratorio se detectó una policitemia (hematocrito de $63 \%$ y hemoglobina de $26 \mathrm{~g} / \mathrm{dL}$ ), con leucocitos y plaquetas normales. $\mathrm{Al}$ examen físico destacaba un eritema plantar. El examen de orina fue normal, así como un holter de ritmo cardiaco y la radiografía de tórax (Figura 1).
La ecografía abdominal mostró un tumor sólido en el riñón derecho, sin otros hallazgos patológicos. La tomografía axial computarizada (TAC) de abdomen y pelvis confirmó una masa sólida en el tercio inferior del riñón derecho, homogénea, sin calcificaciones, de márgenes bien definidos, de $6,9 \times 6,5 \times 4,8 \mathrm{~cm}$ (Figura 2).

Dado estos hallazgos y la imposibilidad de descartar una neoplasia maligna, se procedió a realizar una nefrectomía parcial derecha abierta (Figura 3).

La porción resecada del riñón derecho contenía un tumor de $6,5 \times 5,3 \times 3,5 \mathrm{~cm}$ (Figura 4). El análisis microscópico mostró pequeñas células hipercromáticas, con patrón tubular y glomeruloide, además de células estromales fusadas de núcleos hipercromáticos. No se evidenció invasión vascular ni linfática (Figura 5). El informe definitivo fue de adenoma metanéfrico.

Después de 2 años de la cirugía, el paciente se encuentra sano, sin evidencias de recurrencia, con buena función renal (creatinina sérica de 0,8 $\mathrm{mg} / \mathrm{dL}$ ) y hematocrito de $48 \%$ (hemoglobina de $16,3 \mathrm{~g} / \mathrm{dL})$. 

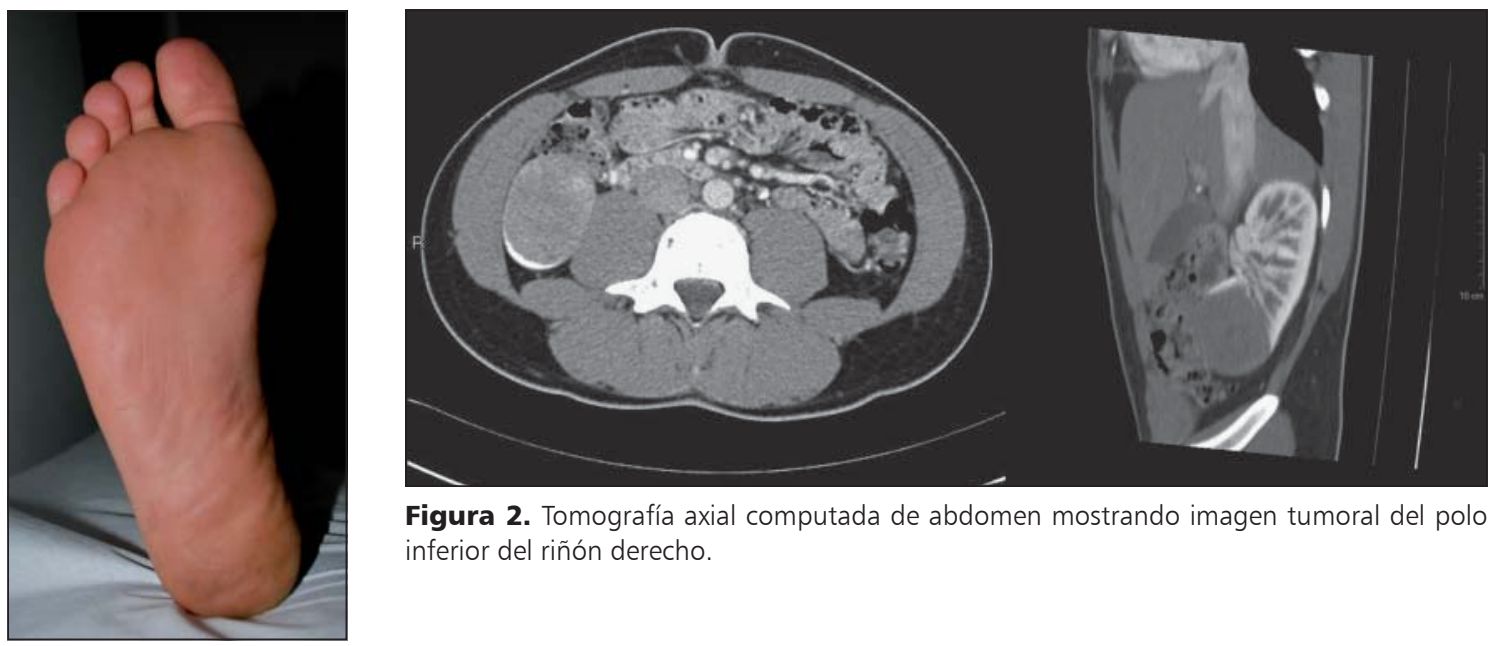

Figura 2. Tomografía axial computada de abdomen mostrando imagen tumoral del polo inferior del riñón derecho.

Figura 1. Eritema plantar.
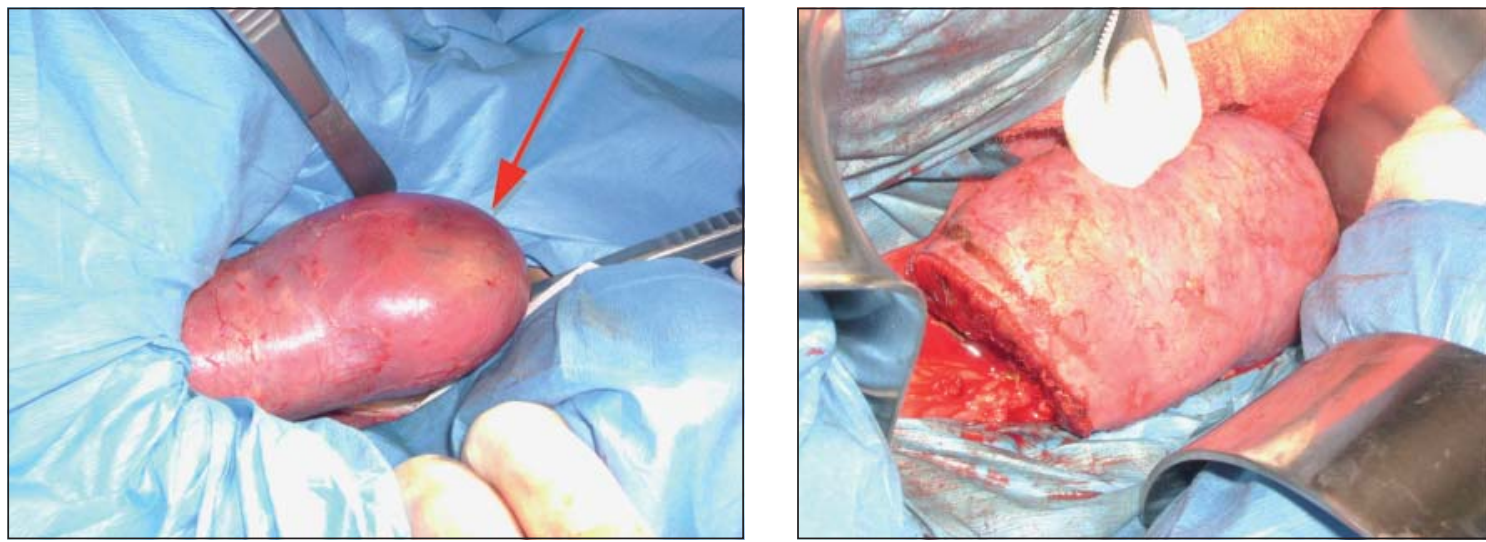

Figura 3. Nefrectomía parcial derecha. A la izquierda, tumor renal derecho de polo inferior (flecha). A la derecha, riñón remanente.

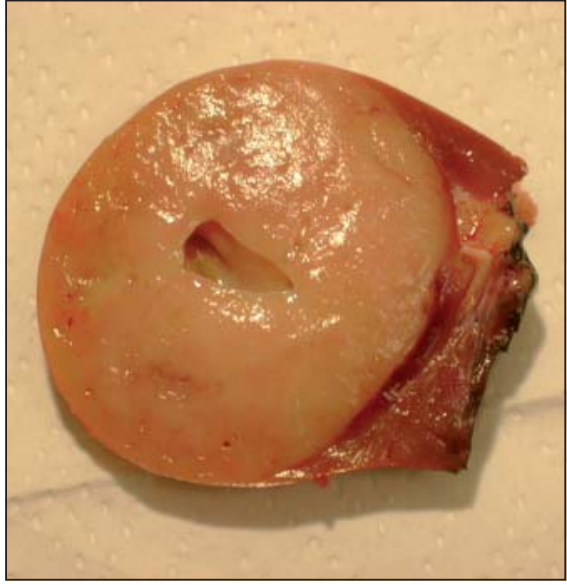

Figura 4. Visión macroscópica del tumor.

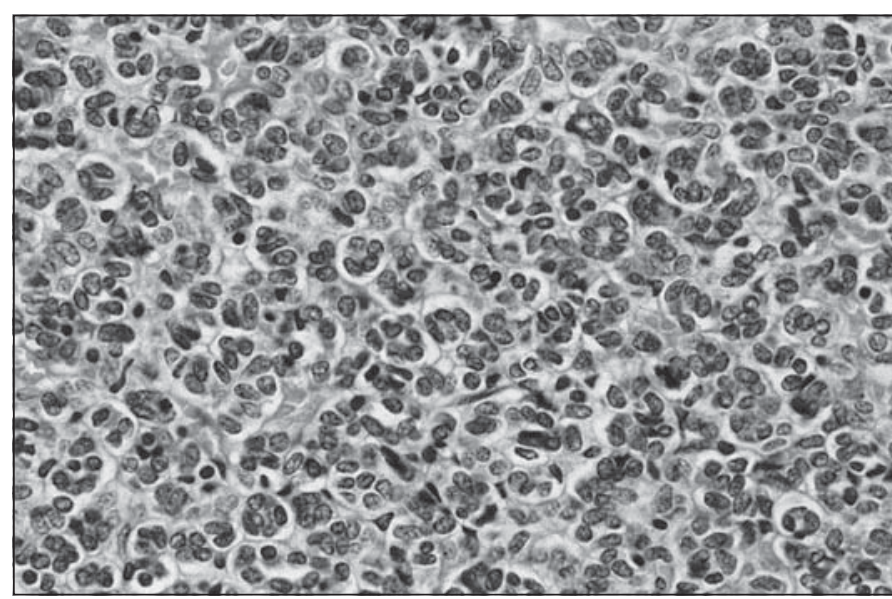

Figura 5. Adenoma metanéfrico clásico. Pequeñas células intensamente basofílicas agrupadas en patrón acinar ${ }^{8}$. 


\section{Discusión}

Davis y cols describieron la serie más grande de pacientes portadores de AM, clasificándola como una lesión renal benigna, poco frecuente, con patrón histológico característico, de gran tamaño y que se presentaba, en un número no despreciable de casos $(12 \%)$, con policitemia ${ }^{1}$. Estos hallazgos fueron también descritos por otros autores ${ }^{5}$. Sin embargo, la presentación más frecuente de estos tumores es el hallazgo incidental ${ }^{6}$. El AM puede afectar a pacientes de cualquier edad, con su mayor incidencia en la quinta década de la vida. La relación hombre-mujer es de 2:1. Su tamaño varía de 3,0-6,0 cm y son unilaterales en la mayoría de los casos. Algunas veces están rodeados por una delgada pseudocápsula. Las calcificaciones están presentes en aproximadamente $20 \%$. Focos de hemorragia y necrosis no son infrecuentes ${ }^{2}$.

Histológicamente, estos tumores presentan pequeñas células epiteliales altamente basofílicas, que forman pequeños acinos $y$, ocasionalmente, estructuras tubulares o papilares ${ }^{7}$.

Por otro lado, la eritromelalgia es una afección que se caracteriza por un dolor urente y eritema de las extremidades. Los pies se comprometen con mayor frecuencia que las manos. Puede ser primaria (llamada eritermalgia) o secundaria. Las causas más frecuentes de la variante secundaria son los trastornos mieloproliferativos como la policitemia verdadera y la trombocitosis esencial. Causas menos frecuentes son fármacos (ej.: bloqueadores de los canales del calcio), enfermedades del mesénquima (ej.: lupus eritematoso sistémico) y síndromes paraneoplásicos. Los pacientes presentan crisis de sensación urente en las extremidades, que se desencadenan con la exposición a ambientes calientes y se agrava con la posición declive ${ }^{8}$.

En este caso, la asociación de policitemia y tumor renal sólido, específicamente un AM en un hombre joven, es rara $(12 \%)^{1}$. Las alternativas diagnósticas preoperatorios eran un tumor de Wilms, un carcinoma de células renales o un tumor desconocido.

El diagnóstico diferencial histopatológico es difícil, en especial con el tumor de Wilms. Casos en que se ha reportado enfermedad metastásica, constituyen un error diagnóstico inicial en la mayoría de éstos ${ }^{9}$.

No se planteó una biopsia percutánea, por considerarse un tumor con clara indicación quirúr- gica. Cabe mencionar que la biopsia por punción es indeterminada en $10-15 \%$ de los casos, existen falsos negativos en 1-2\% y algunos tumores benignos pueden coexistir con cáncer (ej.: oncocitoma y carcinoma de células renales $)^{10,11}$.

En manos experimentadas y casos seleccionados, la nefrectomía parcial laparoscópica podría considerarse una alternativa a la nefrectomía parcial abierta en tumores renales $\mathrm{pT} 1 \mathrm{~b}^{12}$.

\section{Conclusión}

Dada la historia natural del AM, su rareza y la falta de elementos clínicos y radiológicos que permitan establecer un diagnóstico definitivo, el AM sigue siendo un diagnóstico histopatológico. Por este motivo, todo tumor sólido del riñón debe ser considerado como potencialmente maligno y tratado acorde a este principio. Ante la sospecha clínica de un tumor benigno o un AM, debiera plantearse una cirugía conservadora. La biopsia rápida (intraoperatoria) puede ser de ayuda para conservar el riñón, en especial en tumores grandes (entre 4 y $7 \mathrm{~cm}$ ), en los cuales la indicación de cirugía conservadora es, cada vez, menos discutible ${ }^{13}$.

\section{Referencias}

1. Davis C, Barton J, Sesterhenn I, Mastofi F. Metanephric adenoma: clinicopathological study of fifty patients. Am J Surg Pathol 1995; 119: 1101-14.

2. Jones E, Pins M, Dickersin G, Young R. Metanephric adenoma of the kidney. A clinicopathological, immunohistochemical, flow cytometric, cytogenetic and electron microscopic study of seven cases. Am J Surg Pathol 1995; 19: 615-26.

3. Renshaw A, Freyer D, Hammers Y. Metastatic metanephric adenoma in a child. Am J Surg Pathol 2000; 24: 570-4.

4. Arroyo M, Green D, Perlman E, Beckwith J, Argani P. The spectrum of metanephric adenofibroma and related lesions: Clinicopathologic study of 25 cases from the National Wilms Tumor Study Group Pathology Center. Am J Surg Pathol 2001; 25: 433-44.

5. Henniger R, Beckwith J. Nephrogenic Adenofibroma. A novel kidney tumor of young people. Am J Surg Pathol 1992; 16: 325-34.

6. Renshaw A. Subclassification of renal cell neoplasms: An update for the practicing pathologist. Histopathology 2002; 41: 283-300.

7. Wein A, Kavoussi L, Novick A, Partin A, Peters C. 
Campbell-Walsh Urology, 9th edition. Saunders, 2007. Capítulo 47.

8. Fauci A, Braunwald E, Kasper D, Hauser S, Longo D, Jameson J. Harrison's Principles of Internal Medicine. $16^{\text {th }}$ edition. McGraw-hill. 2005. Página 627.

9. Pins A, Jones E, Martul E. Metanephric adenoma-like tumors of the kidney: Report of 3 malignancies with emphasis on discriminating features. Arch Pathol Lab Med 1999; 123: 415-20.

10. Herts B, Baker M. The current role of percutaneous biopsy in the evaluation of renal masses. Semin Urol Oncol 1995; 13: 254.
11. Kummerlin I, Ten Kate F, Smedts F, Horn T, Algaba F, Trias I. Core biopsies of renal tumors: a study on diagnostic accuracy, interobserver and intraobserver variability. Eur Urol 2008; 53: 1219.

12. Thompson RH, Siddiqui S, Lohse CM, Leibovich BC, Russo P, Blute ML. Partial versus radical nephrectomy for 4 to $7 \mathrm{~cm}$ renal cortical tumors. J Urol 2009; 182 (6): 2601-6.

13. Ljungberg B, Cowan NC, Hanbury DC, Horam, Kuczyk MA, Merseburger AS, Patard JJ, Mulders PF, Sinescu IC. EAU guidelines on renal cell carcinoma: the 2010 update. Eur urol 2010; 58 (3): 398-406. 